\title{
Outcome Oriented Academia-Industry Handshaking: Improvised Strategy for Delivering Industry-Ready Engineers
}

\author{
Prakhar Mathur ${ }^{1}$, Sanat Kumar Singh ${ }^{2}$, Madhuri Kumari ${ }^{3}$ \\ ${ }_{1,2,3}$ Department of Civil Engineering, Amity School of Engineering and Technology, Amity University Uttar Pradesh, Sec-125, \\ Noida, U.P-201303 \\ ${ }^{1}$ prakharmat93@gmail.com \\ ${ }^{2}$ sanatsingh68@gmail.com \\ ${ }^{3}$ mkumari@amity.edu
}

\begin{abstract}
This paper is an attempt to identify the gaps in engineering education framework which is failing to deliver market-ready professionals in real sense. A multi-layered analysis of existing engineering education practices was carried out to understand the significant reasons. The methodology of course delivery and evaluation has been critically examined. Further, the implementation aspect of industry-academia collaboration has been analysed. It has been observed that the academia has designed multiple options for engaging industry like guest lectures, workshop, industry visits, conferences etc. The main issue with this model is that there is no defined parameter to gauge the outcome of such academia-industry interaction. Many successful attempts have been carried out by academia to collaborate with industry for incubating the ideas but this doesn't contribute to imparting work-skills to the students. In absence of well-defined benefits to the industry, their participation in this collaboration appears to be limited. This study proposes an improvised strategy of outcome based academia-industry handshaking. The proposal includes the possible implementation methodology which can be adopted, its economic viability and benefits for industry, academia and students.
\end{abstract}

Keywords: Engineers, Industry, Academia, Collaboration

Corresponding Author

Madhuri Kumari, Department of Civil Engineering, Amity School of Engineering \& Technology, Amity University Uttar Pradesh, Sec-125, Noida, U.P - 201303; $\underline{\text { mkumari@amity.edu }}$

\section{INTRODUCTION}

Our previous generations were in an era of politics and war but now our focus is being shifted towards development and we are in grave need for the youth to take up nation building professions especially engineering. Forthwith there is a tremendous demand and opportunity for all kinds of engineers like civil, mechanical, chemical, electrical and computer engineers. A plus point for India is that already a majority of youth is inclined towards these disciplines and in fact every year 1.5 million engineering graduates pass out. Indian engineers are striving in almost every field not only in our own country but also worldwide. As a matter of fact the CEO of Google, the largest multinational technology company of the world is Sundar Pichai who is the product of Indian Engineering Education System of India.

The flip side of the coin is that where there are exceptions like the aforementioned, the generic ground reality is quite different. While the quantity of engineers is ample the quality is not up to the required international standards. An unfortunate truth of our society is that upto $90 \%$ of Indian engineers are unemployable to the extent that around one fifth to one third of engineering graduates have the risk of being unemployed. This is due to varied and numerous gaps in our current educational system and also because of lack of updation of curriculum, outdated teaching methods, resources unavailability and antiquated educational focus. Now it is the right time for India to make some necessary changes in engineering education system to put our country on the path of rapid development. To solve this complex real life problem an ingenious approach need to be taken. 


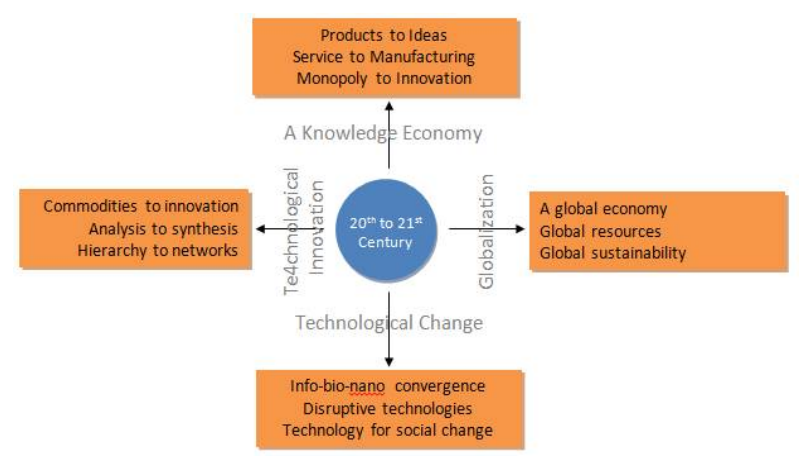

Fig. 1 Changing forces in $21^{\text {st }}$ Century

\section{EXISTING CONVENTIONAL EDUCATION SYSTEM}

Our education system is old and because no updation and upgradation has been brought about, the system has been rendered inefficient and ineffective pertaining to the contemporary demands.

\section{A. Marks oriented}

The current evaluation system relies on a series of testing through written examinations and assigning marks for each test. More weightage is given to theoretical examination taken at end of the semesters rather than practical and continuous evaluation. As a result students only practice previous examinations and standard repetitive questions and are able to score highly in these exams. A major setback of this system is that innovation and ingenuity is not promoted, not accepted and even penalized sometimes. Also implementation of practical examinations is improper as the timeframe is insufficient and the equipment required are in short supply to appropriately evaluate every student.

\section{B. Lacking innovation}

Research and development, product development, advancement in service industry is the backbone of any nation. While disciplines like nanotechnology and biotechnology are exhibiting flourishing research throughout India engineering is specifically lacking in this regard. This is due to the fact that currently the environment itself is not congenial and motivating for scientists and the resources needed are very difficult to amass. The tools and technology required is outdated and insufficient. As there is a requirement of financial support in this area from the government, educational institutions and industry which is not available innovation is suffering. Another perspective is that the problems/projects given at the college level should be more challenging, complex \& real life resulting in ingenious exceptional solution. For instance the invention of pen drive, the idea of it originated from the need of portable devices. The primary resolution was the invention of floppy disk which the upgraded to $C D$, pen drives, flash drives and now Microsoft One Drive. Another example is the invention of Tunnel Boring Machine (TBM). Construction of the Thames Tunnel in 1843 posed a new challenge of tunnelling beneath a navigable river. This led to the introduction of a new concept of shield tunnelling which lead to invention of TBM changing tunneling forever.

\section{Deficient Communication Skills}

Mastery in this skill is a necessity for an individual from any sphere of life and is quintessential for engineers as their job includes collaborating with individuals from wide and varied backgrounds. Indian engineers are known to be famous for their technical expertise but where they are majorly lacking is in communication skills. This is potential problematic and counterproductive because after all their technical hard work, as they are unable to express their ideas their work does not get support and recognition.

\section{Language barrier}

The medium of language for studying engineering plays a vital role for becoming a qualified engineer. The fundamentals of engineering can be better understood if students are familiar with the language taught to them. India is a diverse country and different languages are spoken in different parts of the country and therefore the transition from secondary school to engineering colleges is difficult for the students. As a matter of fact in Tamil Nadu nearly 70 per cent of students who joined engineering education in 2011-12 came from Tamil medium schools. Therefore for becoming a better engineer the problems arising due to language barrier needs to be minimized.

\section{E. Industry Interaction}

For students to become industry ready when they graduate it is very important that they get proper industry exposure during their engineering education. The industry student interaction should be given emphasis in curriculum so that the students are exposed to real life scenario and the complex problems the industry face. The R\&D laboratories sponsored by the industries can be opened in the institute which will be beneficial for both the parties as it will be economical for the industry to set up their laboratory in an institute and the students from the institute will be able to have an in hand experience with latest technology.

\section{F. International Exposure}

Importance of international exposure has already been acknowledged by the top institutes of the nation. Work is already being done to collaborate with international universities and global firms to undertake multidimensional and multi-discipline projects. The pace of this development and the en masse adoption is an issue. The benefits of exposure to this resource can be both for the faculty and students. The faculty gets to analyse their curriculum, way of teaching and students - faculty interaction whereas students get to experience broad global perspectives, diverse environment, latest technology and varied cultures. Lack of this exposure can create engineers who are highly capable and efficient in our own country but are unable to perform in global scenarios.

\section{G. Improper practical training}

Practical, hands-on training is crucial in the engineering education program for engineering graduates to be industry ready after their graduation. Today there is a huge demand for engineers in their respective sector and yet many are unemployed, the reason being the industry does not want to take the freshers as they are lacking practical skill. The

\section{JEË}


industry has to provide 3 to 12 months of training to the graduates before they finally get into the industry. This increases industry's expenditure even after they hire graduates with a technical degree. Skill building and practical training knowledge is not given equal importance as academics and consequently the graduate lack the ability of practical application of their theoretical know how.

\section{H. Fundamentals}

The fundamentals taught in the freshman year of college form the foundation for a student pursuing engineering. The current education system imparts most the essential basics required but now there is a need to expand the definition of the fundamentals. Apart from universally accepted technical courses like engineering analysis, solid mechanics, programming methodology courses like biotechnology, engineering economy, Introduction to Optimization should also be taught.

\section{Jobs}

According to the 'The News Minute', around 1.5 lakh engineers were not placed in the year of 2014. The New Indian Express stated that only $20 \%$ of engineering graduates are employed in accordance with their qualifications, $10 \%$ are underemployed and a whopping $70 \%$ are entirely unemployed. These facts depict that while the student enrolment in engineering is increasing rapidly the quality of these engineers is not increasing, creating an area of concern.

\section{J. Entrepreneurship}

An important attribute missing is the promotion and endorsement of entrepreneurship. The reason behind this void is that the Indian environment and culture itself is not congenial as mindset of workforce is still job centric. Also the resources and financial funding required for these kinds of ventures is wanting. Entrepreneurship is essential for a developing country like ours as it creates individuals capable of generating jobs instead of increasing number of job aspirants.

\section{SKILl REQUIRED}

The Indian existing educational system is more than a century old and has always been revered throughout the globe. Indian engineer's skills and technological knowledge were also recognized as first class. Now the question is that it has always been this way so why should we change it? The basic problem is that now the world is changing at an unprecedented pace and while our educational system was sufficient in earlier times it is just not able to cope up with this changing environment. The consequence of the numerous loopholes and disadvantages of the existing engineering education system is birth a relevant skill deficient in students. A cluster of missing skills are - good communication skills, physical sciences and engineering science fundamentals, ability to identify, formulate, and solve engineering problems, system integration, cultural awareness in the broad sense (nationality, ethnicity, linguistic, gender, sexual orientation) economics and business acumen, high ethical standards, integrity, and global, social, intellectual, and technological responsibility, critical thinking, willingness to take calculated risk, ability to prioritize efficiently, project management, teamwork skills and ability to function on multidisciplinary teams, entrepreneurship and intrapreneurship, ability to use new technology and modern engineering tools necessary for engineering practice, data interpretation and visualization, security knowledge (cyber, data, etc.), leadership, application based research and evaluation skills, ability to create a vision, flexibility and the ability to adapt to rapid change, ability to deal with ambiguity and complexity, innovation, technical intuition/metacognition, conflict resolution, ownership and accountability. The demands of the industry have changed and so there is a requirement of modifying India engineering education to supply the industry requisite skills. The reason behind these demands and their implications for some skills that the industry needs and can help inculcate into students with effective industry-academia collaboration has been explored in the following passages.

\section{Growth of Institutions in the last six years}

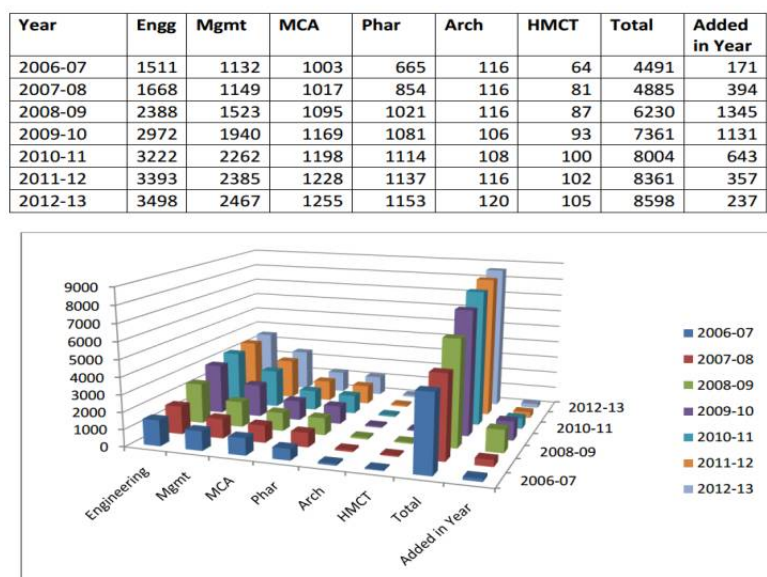

Growth of Student Intake in the last six years
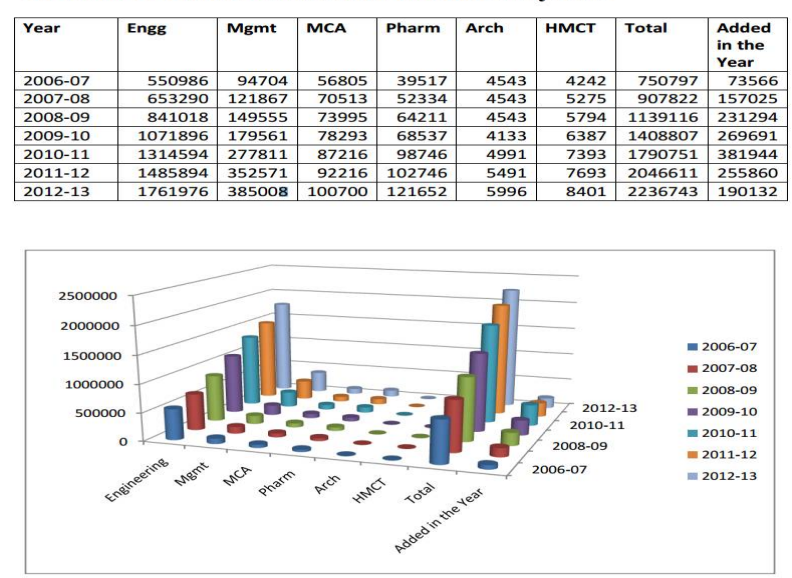

Fig. 2 Programme-wise growth of institution and students enrolment from 2006-13 
The statistics provided by the AICTE (All India Council of Technical Education) illustrate that there is a rapid increase in the growth of engineering institutions in India and as well the growth of student intake. But the fact remains is that still there is huge unemployment rate in this sector inspite of India being a developing country and there is massive requirement of engineers for the development of economy. According to the survey conducted by NASSCOM three years ago exhibit that $90 \%$ Graduates and $75 \%$ Engineers are unemployable. The reason behind this is that the engineering graduates who are passing out each year are not able to meet the requirements of the industry. The engineering institutes are not able to produce industry ready engineers who are ready to take on the real life projects and can play their role in the growth of an industry. The industry is looking for an engineer who possess traits like- leadership, capability to take risk, business \& economic understanding, project management skills, practical knowledge applicability, technical knowledge etc. which has been explained in the following sections and also the solutions which are needed to be implemented to improve the education quality which will help in bridging the gap of huge unemployment in the engineering sector.

\section{A. Practical knowledge applicability}

The industry is looking for an individual whose technical fundamentals are strong and can apply their theoretical knowledge into practice which can be beneficial for its progress. The amalgam of practical skills and technical expertise can help an engineer to resolve complex, unruly problems which he confronts in any real life project. The ability to apply practical knowledge can provide engineers the much needed extra edge for solving any unpredictable predicaments.

\section{B. Flexibility \& adaptability}

Today the world is changing at a brisk pace and it creates new demands and needs every day. This creates various requisite in industry and therefore there is a demand for engineers who are keen to take on new challenges and are willing to thrive on it. Also the engineers should be able to exhibit adaptability in unfavourable conditions like long working hours, frequent delay in project, unanticipated work situations, unpredictable hostile environment etc. The engineers who are able to demonstrate their resilience are in better position to work in fast changing erratic circumstances. The zeal to learn contemporary methods, skills and techniques are indispensable traits for engineering industry.

\section{System Integration}

In engineering, system integration means to bring together the disparate segments of a system and to ensure that they work in perfect harmony. All technical challenges and designs are generally at system level so the students need to be introduced to system integration early in their undergraduate programs. At the professional level every project is multidisciplinary but interrelated while in graduate studies it is not. So system integration skill will help students to adapt to the transition from academia to industry.

\section{Technical skills and engineering tools}

The characteristic that gives an engineer an upper hand in workplace is the knowledge of modern-day technical equipment. This is based on the premise that they are required in almost every phase of job like design, testing, operation, trouble-shooting, recording and analysing data, making calculations and reporting findings. From an employee's perspective, if an employee possesses a unique ability in any field, it can help him to become an invaluable asset for the company. Therefore the need of knowledge of contemporary softwares, latest instruments and cutting edge tools is universally recognized by students, academia and industry.

\section{E. Business Economic knowledge}

The prime importance of this resource is that the engineer must understand the application of his technological expertise to the business and economical aspect of industry. An invention or discovery is useless if it has no real world application. In addition it will aid engineers to comprehend and optimize the businees operation of technically oriented bussinesses. Analyzing the market from business and finance outlook will enable them to achieve techincal innovations pertaining to the current economy needs. Finally skills in technical communication and critical reasoning will also be enhanced.

\section{F. Project Management}

This skill is required by professionals from all disciplines be it international trade, marketing, life sciences, construction or information technology. It facilitates to keep the project on task, on time and on budget. The necessity for engineers to perform in collaboration with multiple individuals and teams, solve complex contemporary problems within stringent timelines creates the demand of this skill. Project management is superset to many professionally relevant skills like risk evaluation, tactical leadership, efficiency in team work, quality management and determination of project scope.

\section{G. Conflict Resolution}

With the onset of large multi-national corporations replacing small scale businesses, the want of conflict resolution has been created as employees are increasingly working in large variegated environments. Collaboration during work causes difference of opinions, different working methodologies \& alternative and sometimes opposing ideas. Here industry looks forward to individuals who actively deploy conflict resolution for problem solving, creating mutual understanding and reducing tension.

\section{H. Willingness to take calculated risks}

This skill differentiates the average from the exceptional. Definite and quantifiable answers to all questions cannot be found, this is where calculated risk taking comes into play. This situation arises frequently in the occupation of an engineer. In civil engineering project execution, environmental factors like earthquakes, slope stability, 
maximum wind pressure cannot be discretely evaluated. To counteract the consequences of aforementioned force an engineer must take calculated risks based on his technical knowledge and experience.

\section{Leadership}

The industry is looking for an individual who can take their company to a new apex in this age of high competitiveness. It is essential to possess leadership traits like the ability to take quick decision in critical situations, the will to take calculated risk, capability to take his subordinates with him and the competence to rise from adversities. As a matter of fact, there is a significant number of CEOs of top 400 fortune companies who hold engineering graduate degree.

\section{J. Capability to create vision}

The capability to predict uncertain future and the ability to take appropriate action is a trait to steer away from any misfortune and to always remain in the summit of competition. Another perspective is the skill to create or invent new ideas in respect of future needs. Some visionaries like Sunil Bharti Mittal, Henry Ford and Larry Page who could anticipate the future market needs irrespective of the discipline have achieved phenomenal success and changed the world for better.

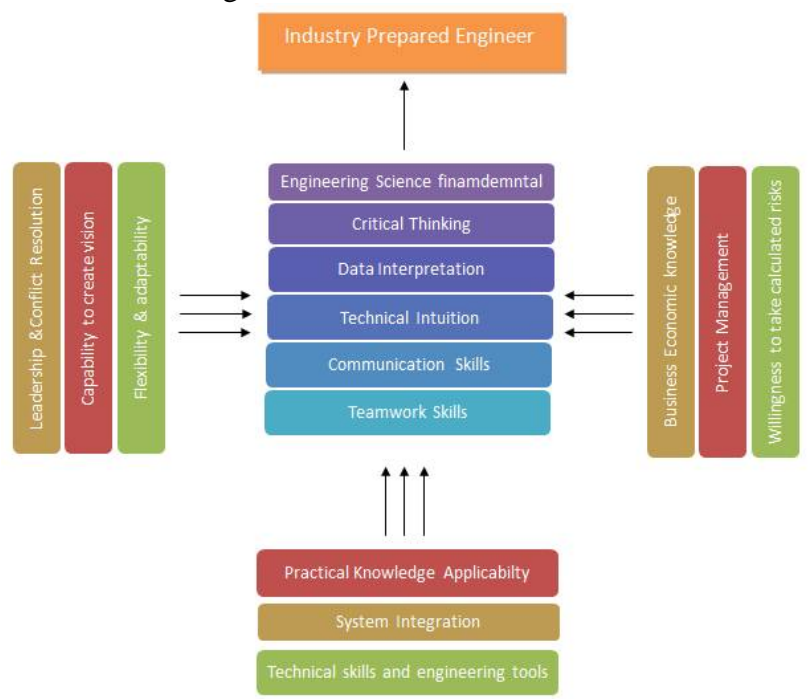

Fig. 3 Elements for making industry prepared engineer: components of engineering education framework and sets of individual skills

\section{Proposed Strategy}

The best practices that can be adopted by the industry in association with the academia to compensate for the outdated conventional system have been discussed in detail.

\section{A. Company engineered PhD, M. Tech., B. Tech. programmes}

In this the university gives an opportunity to corporates to sponsor a specific number of seats in institutions. Funding courses in universities specific to their need helps promote the disciplines that the industry requires. In engineering the majority of students take up core branches like civil, mechanical electrical and computer science. So companies working in nuclear science and chemical sectors can offer scholarships to promote nuclear and chemical engineering courses to increase the deficit talent pool available. Subsidized education and prospects of jobs in funding companies is sure to attract students to pursue such courses. Also these scholars could be given the opportunity to learn directly from the

- Sponsoring organization's professionals alongside the regular course. In addition this opportunity provides the prospect of

- Academia collaboration for company specific R\&D. Therefore R\&D (Research and Development) and CSR (Corporate Social Responsibility) budgets of an organization can be used to finance this investment. The former aids companies to maintain a technical edge over competitors whereas the latter is used for general social betterment.

\section{B. Assignment based seminars}

In engineering institute, there is already a practice of seminars given by the experienced people from industries but now there is a critical need to increase productivity of the seminars. Today the reality is that seminars are unilateral and there is no proper interaction between the students and the experts. Interaction between the two is essential for progressive learning. So instead of only monologue by experts, after instruction assignments should be provided by industry for students to solve. Students should be encouraged to take up these assignments in collaboration with both faculty and industry professional. Also proper follow up after the seminar is required so that the learning process does not end with the seminar. This methodology would help the student to get familiar with the real life complexities which the industry faces and also help to impart attributes like practical knowledge application, flexibility \& adaptability in work and project management.

\section{Connection with alumni}

The role of mentor in producing highly efficient industry ready engineers is very vital as it can help the student in dealing with the various issues regarding their exams, core curriculum, future prospective, project complexities etc. And who can play the role of mentor better than the alumni of that institution since they have previously dealt with the same obstacles in their college time. The alumni with their networking can also help in arranging placements and internships to the students which will not only facilitate the students but will also help in improving the stature of any institute. Therefore it is important for the institution to keep continuing their relationship with their alumni.

D. Industry academia feedback system

This is an extension of all the other solutions. In the current scenario only few colleges inquire for student feedback 
regarding university activities and regarding faculty but an industry academia feedback system is non-existential. For example industry feedback about students placements, internships, seminars, designing research, education and outreach programs, volunteer activities, social events andexperiential outings. This will assist both parties to understand the needs and wants of the other resulting in better collaboration activities.

\section{E. Incubators and angel investors}

Entrepreneurship is what India will sorely need by 2025 . Indian economy is a service provider based economy and infrastructure development and manufacturing are not receiving their due attention. Also most of the Indian youth is and aspires to work for foreign MNCs. The result of this trend is that a lot of money is being siphoned out of the country and competent people who have the capability to start their own ventures are selling themselves short by working for these foreign corporates. Entrepreneurship is the sole solution to this problem. It will make India more autonomous, self-reliant and self-sufficient. Moreover it will escalate the quantity and quality of job opportunities available, reduce imports, increase exports and promote research and development. Colleges are the best platform to inculcate into individuals the practice of entrepreneurship. Promotion of entrepreneurship through establishments of incubators and angel investment funds in universities can be some possible routes. This is something that can be majorly undertaken by the industries.

\section{F. Business and economic knowledge}

The acquaintance of business and economic can be imparted to the engineering students with the help of both industry and academia. The academia can introduce a course for basic economic and business understanding and also the advanced course as an optional for the students, this will help them in understanding the other side of any project beside the technical competence such as project management, and project planning and business impact in any project. The industries can also help in mentoring the students in this discipline by allotting them industry related assignments and making them aware of the business side of their skill. This proficiency will help the engineers in making appropriate, feasible, economical and best decision for the company they are working with.

\section{G. Endowment}

For any institute to become successful and at world par there is huge requirement of endowment given to the institute in the form of endowed scholarships, professorships and fellowships by supporting the talented students, scholars and faculty. The prominence of any institute is based on the patents filed, case study developed and research projects carried out. Therefore for carrying out any development in research there is urgent need of endowment so that the scholars can work without any financial burden. As a matter of fact there is a vast gap in endowment in Indian engineering institutions and the world's leading engineering institutions. Industries can help in endowment by facilitating $R \& D$ (research \& development) and also granting scholarships to the scholars, which will also help them to remain competitive in the market.

\section{H. Shared Labs}

The basis of industry academia integrated labs is space sharing. In this the University provides space for the labs while both contribute funds for developing the requisite infrastructure. While land is available to industry for free or at subsidized rates making it an effective economical option. Moreover the industry gets a pool of well-trained students to offer internship, assistantship or temporary and permanent jobs. With industry's financial support latest technological equipment can be made available to students. The basic tools and instrumentation knowledge can be given by academia faculty while research can be carried out by students especially graduates and $\mathrm{PhDs}$ in collaboration with industry professionals. Some of array of skills which can be imparted to students are ability to identify, formulate, and solve engineering problems, critical thinking, data interpretation and visualization, willingness to take calculated risk, intrapreneurship, innovation, ability to create a vision. In addition it provides an excellent platform for student for networking with industry experts. If administration aspect can be worked out like proper demarcation for access to different resources of labs, then this idea can be highly advantageous for both parties.

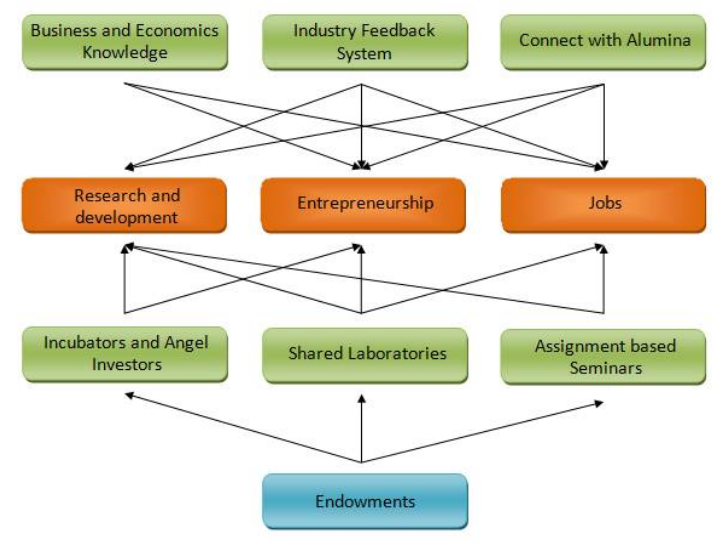

Fig. 4 Proposed model of academia-industry collaboration

\section{CONClusions}

Though the engineering institutes have well laid framework for industry-academia collaboration but the measure for effectiveness of the same is not defined. Owing to nonsymbiotic relationship between academia and industry, the industry participation is very limited. In majority of the cases, the industry experts visits the campus of institution for delivering their know-how and latest trends in the industry which is confined to one-two lectures. This doesn't 
provide considerable orientation of industrial requirement into the students. This lacuna in existing system can be addressed by having improvised strategy of mutually benefitting collaboration. The proposed strategy is to promote company engineered programmes, strong industry mentoring system, collaboration feedback and assessment system, shared labs, incubators and industry designed scholarships for the students.

\section{REFERENCES}

Bidanda, B., and Billo, R., "On the Use of Students for Developing Engineering Laboratories," Journal of Engineering Education, Vol. 84, No. 2, 1995, pp. 205-213. Bordogna, Joseph, Eli Fromm, Edward W. Ernst. "Engineering Education: Innovation Through Integration", Journal of Engineering Education, January, 1993, pp. 38.

Educating the Engineer of 2020: Adapting Engineering Education to the New Century (2005), ISBN: 0-309-550084

Feisel, L.D., and Peterson, G.D., "The Challenge of the Laboratory in Engineering Education," Journal of Engineering Education, Vol. 91, No. 4, 2002, pp. 367-368.

Feletti, G.I. (eds.) The challenge of problem-based learning, 2nd ed, Kogan Page, London. 173-180, (1997).

Froyd, J. E., Layne, J., \& Watson, K. L. (2006). Issues Regarding Change in Engineering Education. Paper presented at the Frontiers in Education Conference.

KoIb, D.A., Experiential Learning: Experience as the Source of Learning and Development, PrenticeHall, Englewood Cliffs, N.J., 1984.

NRC, The Impact of Academic Research on Industrial Performance. Washington, D.C.: National Academies Press, 2003.

S. Abd-Elall, C. Reise, and G. Seliger, A dynamic model for matching job market qualifications demand and educational market qualifications supply, presented at the The 8th Global Conference on Sustainable Manufacturing, Abu Dhabi University, UAE, 2010

Shamoo, Adil E.; Resnik, David B.; Collaboration between Academia and Private Industry; Oxford Press; Feb 2009; Page 81-98.

Sullivan, William M., "Markets vs. Professions: Value Added?, Daedalus (2006)

The Influence of Technology on Engineering Education (1995), ISBN ; 0-8493-2639-7

Woods, D.R., Issues in implementation in an otherwise conventional programme. In Boud, D.\& Employability Skills Profile: What are Employers Looking For? The Conference Board of Canada, Ottawa, 1993.

http://www.aicteindia.org/downloads/Growth\%20of\%20Student $\% 20$ Intake \%20in\%20the\%201ast\%20six\%20years.pdf, 28/09/2015

http://www.aicte-

india.org/downloads/Growth\%20of\%20Institutions $\% 20 \mathrm{in} \%$ 20the\%201ast\%20six\%20years.pdf, 28/09/2015

\section{About Authors}

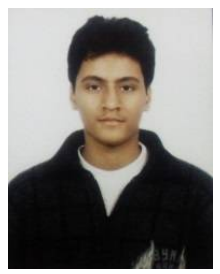

Prakhar Mathur was born in New Delhi, India in 1993. He is an undergraduate student and pursuing B. Tech. Civil Engineering from Amity University. $\mathrm{He}$ is a member of Institution of Civil Engineers (ICE), UK and American Society of Civil Engineers (ASCE). He is currently in his final year and his area of interest is Construction Engineering and Management.

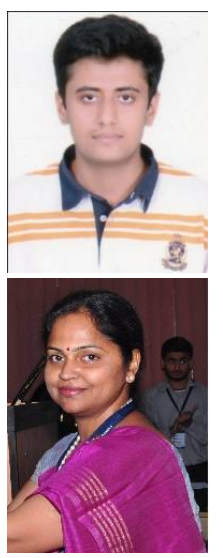

Sanat Kumar Singh was born in India in $1995 . \mathrm{He}$ is pursuing B. Tech (Final year) in Civil Engineering from the Amity University, Noida, India (2012-2016). He is a member of Institution of Civil Engineers (ICE), UK. He wants to do master in Structural Engineering and to do further research in that field.

Madhuri Kumari is working as Associate Professor in Department of Civil Engineering, Amity School of Engineering and Technology, Amity University Uttar Pradesh, Noida, U.P. She has received her M.Tech. degree in Hydraulics and Water Resources Engineering from Institute of Technology, Banaras Hindu University and B.E degree in Civil Engineering from Andhra University. She has vast industry experience of $11+$ years and academic experience of 5+ years. She has worked in various sectors like airlines, water resources, elearning etc. 